\title{
Síndrome de Miller Fisher recurrente
}

\author{
ROBERTO PORTILLO ${ }^{1}$, ÉDGARD ROJAS $^{1}$, JOSÉ VERA $^{1}$, ORLANDO LOO $^{1}$, WILDER GONZALES $^{1}$ \\ ${ }^{1}$ Hospital Guillermo Almenara Irigoyen, Servicio de Neurología. Lima, Perú.
}

\begin{abstract}
Resumen
Presentamos el caso de una mujer de 69 años de edad con antecedente de hipertensión arterial y Síndrome de Miller Fisher recurrente hospitalizada en tres oportunidades. Las manifestaciones clínicas en sus respectivos ingresos por emergencia se caracterizaron por cefalea, diplopia y trastorno de la marcha, evidenciándose en el examen neurológico la triada clásica de oftalmoplejia, ataxia y arreflexia. Se describe los resultados de exámenes complementarios: neuroimágenes, líquido cefalorraquídeo, electromiografía y anticuerpo antigangliosido GQ1b. La recuperación de su enfermedad fue completa. En el seguimiento está asintomática.
\end{abstract}

Palabras claves: Miller Fisher; Oftalmoplejia; Ataxia; Arreflexia; Recurrente.

\begin{abstract}
Recurrent Miller Fisher syndrome
Abstract

We present the case of a 69 year-old woman who had two recurrent Miller Fisher syndrome and arterial hypertension. The clinical findings at emergency admission were headache, dyplopia, and gait disorder. Clinical examination showed the classic triad ophtalmoplegia, ataxia and arreflexy. We describe neuroimaging, spinal fluid, electromyography and anti gangliosid GQ1b antibody results. Clinical recovery was total and she is now asymptomatic.
\end{abstract}

Key words: Miller Fisher syndrome; Ophtalmoplegia; Ataxia; Arreflexy; Recurrence.

\section{CASO CLÍNICO}

Paciente mujer de 69 años, natural de Junín y procedente de la ciudad de Lima, diestra, con estudios de primaria incompleta. Refiere antecedente de hernioplastia en 1990 e hipertensión arterial en tratamiento regular desde 1992.

A continuación se describe por separado cada hospitalización.

\section{PRIMERA HOSPITALIZACIÓN}

Fecha de ingreso 25 de abril de 1996, con tiempo de enfermedad de 10 días, caracterizado por cefalea occipital, con niveles de presión arterial elevado: Un día después se agrega inestabilidad para la marcha, visión borrosa, parestesias en hemicara, paladar y mano izquierda. Tres días antes de su ingreso presentó asimetría facial izquierda y disminución de fuerza de mano izquierda. Al examen clínico frecuencia cardiaca (FC) 72/min, presión arterial (PA) 160/90, frecuencia respiratoria (FR) $18 / \mathrm{min}$, afebril. Paciente en regular estado general, nutrición e hidratación, facies dolorosa. Aparato cardiovascular: ruidos cardiacos rítmicos y taquicárdicos. Neurológico: Despierta, orientada, oftalmoplejia III, IV y VI, bilateral, con midriasis paralítica; paresia facial periférica izquierda, no déficit motor, arreflexia generalizada, marcha atáxica, no signos meníngeos. Tomografía axial computarizada (TAC) fosa posterior sin hallazgos significativos. Líquido cefalorraquídeo (LCR) transparente, células 01 (100\% linfocitos), sin gérmenes; glucosa $5,7 \mathrm{mmol} / \mathrm{L}$, proteínas $55 \mathrm{mg} / \mathrm{dL}$, ADA 1,26 U, Papanicolaou (Pap) negativo. Tratamiento usado: captopril, 
metilprednisolona, Recuperación clínica completa.

\section{SEGUNDA HOSPITALIZACIÓN}

Fecha de ingreso 5 de noviembre de 2000, con tiempo de enfermedad de 5 días, caracterizado por debilidad de miembros inferiores que progresivamente le dificulta la marcha. Dos días antes del ingreso se agrega cefalea global intensa y visión borrosa, náuseas y vómitos; refirió parestesias en paladar, lengua y en miembros inferiores. Al examen clínico, FC 70/min, PA 140/90, FR 16/min, afebril. Neurológico: despierta, orientada, ptosis palpebral a predominio izquierdo oftalmoplejia III, IV y VI bilateral, con pupilas normales, sin déficit motor, arreflexia generalizada, sensibilidad conservada, marcha atáxica, no signos meníngeos. TAC cerebral sin hallazgos significativos. Electromiografía: Hallazgos compatibles con polineuropatía sensitivo motora tipo axonal. LCR transparente, células 02 sin gérmenes, glucosa $3,4 \mathrm{mmol} /$ L, proteínas $35 \mathrm{mg} / \mathrm{dL}$, globulinas negativo, Pap negativo. Tratamiento usado: captopril, metilprednisolona, prednisona. Con recuperación clínica completa.

\section{TERCERA HOSPITALIZACIÓN}

Fecha de ingreso 11 de julio de 2003, con tiempo de enfermedad de 8 días, caracterizado por cefalea global intensa en región occipital; tres días después se agrega parestesias en hemicara izquierdo, incluyendo paladar y lengua. Tres días antes de su ingreso presenta inestabilidad para la marcha, persistiendo cefalea. En su hospitalización se agrega ptosis palpebral y debilidad de músculos oculomotores. Al examen clínico FC 86/min, PA 150/80, FR 18/min, afebril. Neurológico: Despierta, orientada, oftalmoparesia III, oftalmoplejia IV y VI bilateral, sin déficit motor, arreflexia generalizada, sensibilidad conservada, marcha atáxica, no signos meníngeos. Exámenes de rutina dentro de valores normales, excepto triglicéridos elevados. TAC fosa posterior sin hallazgos significativos. Resonancia magnética nuclear (RMN) cerebral: Perdida volumétrica de ambos hemisferios. Espirometría normal. Electromiografía: Latencia distal sensitiva elongada (sural). Amplitud disminuida del potencial. No evidencia de compromiso motor. LCR transparente, células 01 , no gérmenes, glucosa $3,0 \mathrm{mmol} / \mathrm{L}$, proteínas $31 \mathrm{mg} / \mathrm{dL}$, globulinas negativo, tinta china negativo. Anticuerpo sérico antigangliosido GQ1b positivo. Tratamiento usado: captopril, prednisona, genfibrozilo. Con recuperación clínica completa.

\section{DISCUSIÓN}

El Síndrome de Miller Fisher (SMF) es la variante clínica más frecuente del Síndrome de Guillain Barré, aunque sólo se presenta en 3 a $5 \%$. Es usualmente una enfermedad monofásica de comienzo subagudo ( $\left.{ }^{1}\right)$. La frecuencia en la recurrencia del Síndrome de Guillain Barré es de 1 a $6 \%$. En cambio, la recurrencia en el Síndrome de Miller Fisher es excepcional. Hay pocos casos reportados de SMF. La triada clásica de oftalmoplejia, ataxia y arreflexia, con mínima o ninguna debilidad de extremidades ( $\left.{ }^{(}\right)$, es frecuentemente precedida por una enfermedad viral $\left({ }^{1}\right)$. El SMF es un ataque inmunológico sobre el axón terminal $\left({ }^{2,3}\right)$, cerebelo $\left({ }^{2,4}\right)$ y posiblemente el tracto corticoespinal $(2,5)$. Esta triada clínica se presentó en las tres hospitalizaciones de la paciente, aparte de síntomas de parestesias en hemicara izquierda, paladar y lengua. Atribuimos su cefalea presente en las 3 oportunidades a la presencia de comorbilidad, la hipertensión arterial, ya que coincidía con valores elevados de la presión arterial.

Existen pocos casos de SMF recurrente $\left({ }^{6,7}\right)$. Riche y col. reportaron un caso de un varón con tres episodios de recurrencia en el periodo de dieciséis años $\left(^{6}\right)$. Dewarrat y col. comunicaron un paciente que presentó, en diez años, tres episodios similares de oftalmoplejia, ataxia y 
arreflexia, asociado a debilidad orofaríngea y signos de neuropatía sensitiva distal leve ( ${ }^{7}$ ). Vinals y col. describieron otro caso de SMF recurrente $\left({ }^{8}\right)$. Nuestra paciente presentó su primera recurrencia luego de aproximadamente 4 años y la segunda después de casi 3 años. El tiempo promedio desde el inicio de las primeras manifestaciones clínicas hasta la fecha de sus respectivas hospitalizaciones fue de una semana.

El estudio del LCR puede mostrar normo o hiperproteinorraquia discreta $\left({ }^{7}\right)$. En nuestra paciente, en su primer episodio obtuvo los valores de $55 \mathrm{mg} / \mathrm{dL}$. En las otras dos hospitalizaciones, el LCR fue normal, incluyendo su acelularidad.

En los estudios de neuroimágenes (TAC y RMN cerebrales) no hubo hallazgos significativos, a diferencia de un caso reportado por Irzel Teser y col., quienes encontraron una lesión irregular en la zona posterolateral de la protuberancia y pedúnculo cerebeloso derecho, con hiperseñal en T2 $\left({ }^{9}\right)$, espirometría normal.

La oftalmoplejia no es abordable en los estudios electrofisiológicos habituales, por lo que se ha explorado diferentes territorios nerviosos para demostrar la existencia de anomalías en la conducción nerviosa. Se pone de manifiesto en una revisión reciente que diferentes autores están de acuerdo en que existe una disminución en la amplitud de los potenciales de acción sensitivos distales $\left({ }^{10,11}\right)$. En nuestra paciente, la última electromiografía presentó latencia distal elongada en nervio sural y amplitud disminuida del potencial. No se evidenció signos electromiográficos de denervación.

Está ampliamente aceptado que el anticuerpo sérico IgG anti gangliosido GQ1b está asociado con oftalmoplejia en pacientes con SMF. Los títulos de anticuerpo anti GQ1b se encuentran elevados durante un episodio y disminuyen, pero no desaparecen completamente, luego de dos años $\left({ }^{6,7}\right)$. Así, se detecta en más de $90 \%$ de pacientes en la fase aguda y que no se encuentra en los grupos de control de personas sanas, pacientes con esclerosis múltiple y pacientes con esclerosis lateral amiotrófica $\left({ }^{12-14}\right)$. Estos anticuerpos que causan parálisis en la musculatura diafragmática de ratas no son detectados en pacientes en fase de recuperación $\left({ }^{15}\right)$. En nuestra paciente, se corrobora el diagnóstico clínico al ser positivo.

El tiempo promedio de recuperación en SMF es de más de 10 semanas $\left({ }^{16}\right)$. El caso presentado respondió bien a corticoides (metilprednisolona parenteral - prednisona oral), con recuperación total después de finalizar en promedio 8 semanas en los 3 episodios, sugiriendo que los fármacos inmunomoduladores tienen un rol en la fisiopatología de esta entidad para su tratamiento.

\section{REFERENCIAS BIBLIOGRÁFICAS}

1. Sitajayalakshmi S. Recurrent Miller Fisher Syndrome: A case report. Neurology India. 2002;50:365-6.

2. Lo Y, Ratnagopal P. Corticobulbar dysfunction in the Miller Fisher syndrome. Clin Neurol Neurosurg. 2003;105:156-8.

3. Bullens RW, O'Hanlon GM, Goodyear CS, Molenaar PC, Conner J, Willison HJ, et al. Anti-GQ1b antibodies and evoked acetylcholine release at mouse motor endplate. Muscle Nerve. 2000;23:1035-43.

4. Inoue A, Koh C, Iwahashi T. Detection of serum anticerebellar antibodies in patients with Miller Fisher syndrome. Eur Neurol. 1999;42:230-4.

5. Lo Y, Ratnogopal P. Transcranial magnetic stimulation studies in the Miller Fisher syndrome: evidence of corticospinal tract abnormality. J Neurol Neurosurg Pyschiatr. 2001;71:210-4.

6. Riche G, Caudie C, Vial C, Bourrat C. Recurrent Miller Fisher Syndrome and anti-GQ1b antibodies. Rev Med Interne. 1998;19:192-5.

7. Dewarrat A, Regli F, Steck A, Kuntzer T. Recurrent Miller Fisher Syndrome. Significance of anti- GQ1b antibodies. Schweiz Arch Neurol Psychiatr 1995;146:180-4.

8. Vinals M, Anciones B, Cruz Martinez A, Barreiro P. Recurrent Miller Fisher Syndrome associated with brachial neuritis. Neurologia. 1989;4:61-5.

9. Tezer FI, Gurer G, Karatas H, Nurlu G, Saribas O. Involvement of the central nervous system in Miller Fisher syndrome. Clin Neurol Neurosurg. 2002;104:377-9.

10. Calleja J, Garcia A, de Pablos C, Polo JM. Síndrome de Miller Fisher: estudio electrofisiológico evolutivo en cinco pacientes. Rev Neurol. 1998;27:60-4.

11. Fross R, Daube J. Neuropathy in the Miller Fisher syndrome: 
clinical and electrophysiologic findings. Neurology. 1987;37:1493-8.

12. Silva LF, Panfilio CB, Hernandez-Fustes J, HernandezCossio O, Hernandez-Fustes OJ. Síndrome de Miller Fisher y angioma cavernoso. Rev Neurol. 1999;28: 1057-9.

13. Chiba A, Kusunoki S, Shimizu T, Kanazawa I. Serum IgG antibody to ganglioside GQ1b is posible marker of Miller Fisher Syndrome. Ann Neurol. 1992;31:677-9.
14. Yuki N, Sato S, Tsuji S, Ohsawa T, Miyatake T. Frequent presence of anti-GQ1b antibody in Fisher s Syndrome. Neurology. 1993;43:414-7.

15. Roberts M, Willison H, Vincent A, Newsom-Davis J. Serum factors in Miller Fisher variant of Guillain Barre syndrome and neurotransmitter release. Lancet. 1994;343:454-5.

16. Berlit P, Rakicki J. The Miller Fisher Syndrome: review of the literature. J Clin Neuro Ophthalmol. 1992;12:57-63.

Correspondencia:

Dr. Roberto Portillo Vallenas

Hospital Nacional Guillermo Almenara Irigoyen

Unidad de Neurofisiología

Av. Grau 800. Lima 13, Perú

Correo-e:drrobertoportillo@hotmail.com 